\title{
Anticancer Potential of Diiron Vinyliminium Complexes
}

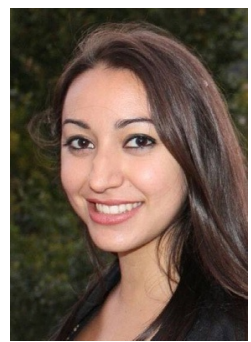

Dalila Rocco

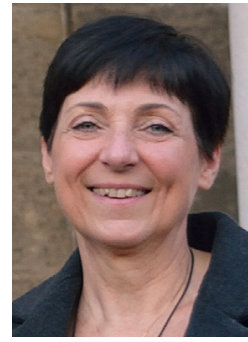

Tiziana Funaioli

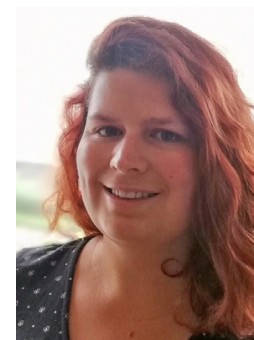

Lucinda K. Batchelor

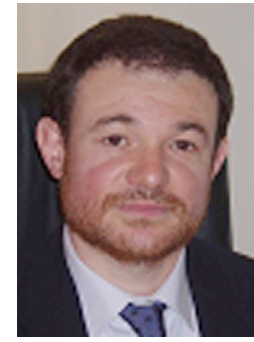

Stefano Zacchini

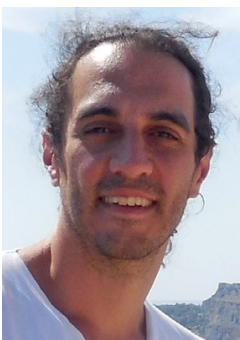

Gabriele Agonigi

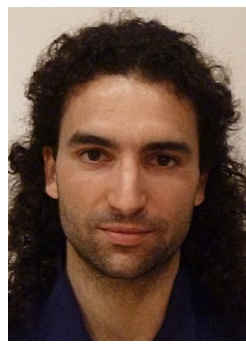

Lorenzo Biancalana

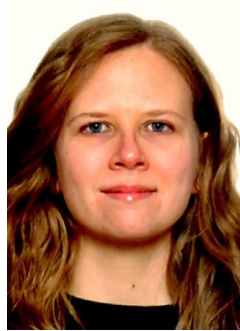

Simona Braccini

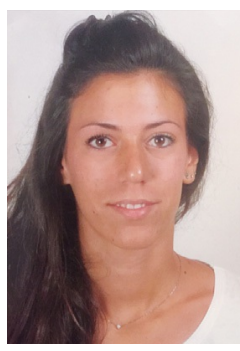

Marina Ruggeri

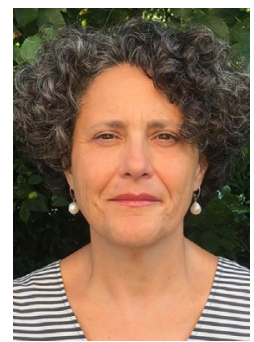

Federica Chiellini

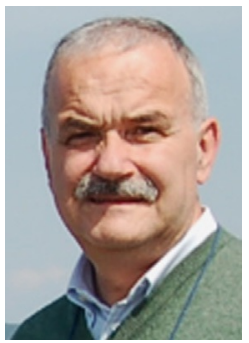

Guido Pampaloni

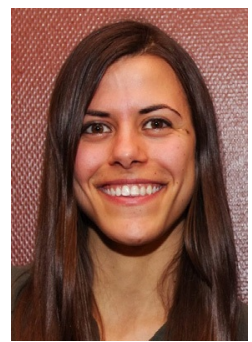

Silvia Schoch

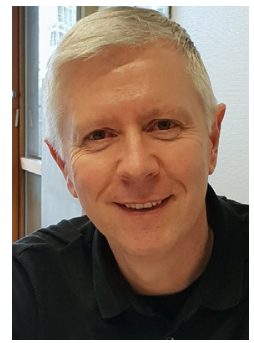

Paul J. Dyson

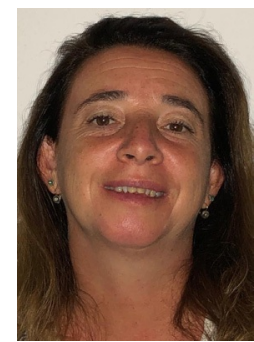

Tarita Biver

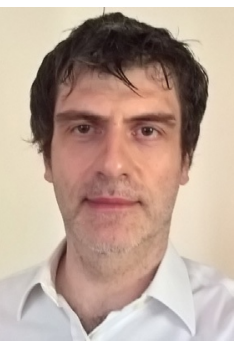

Fabio Marchetti

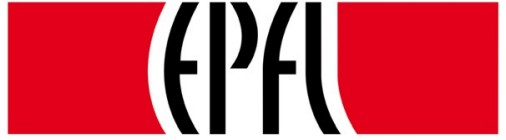

ÉCOLE POLYTECHNIQUE FÉDÉRALE DE LAUSANNE
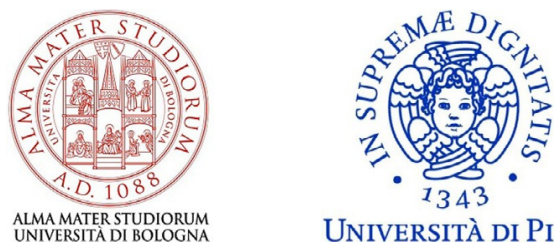

UNIVERSITÀ DI PISA

Invited for the cover of this issue is the group of Fabio Marchetti at the Università di Pisa and Paul J. Dyson at Ecole Polytechnique Fédérale de Lausanne (EPFL). Read the full text of the article at 10.1002/chem.201902885.

\section{What is the most significant result of this study?}

Iron is an earth-abundant and bio-essential element, and there is evidence (even from nature) that two adjacent iron atoms constitute a powerful structural core, in which they may cooperate to provide important reactivity and/or catalytic effects. Our report describes the preliminary assessment of the in vitro antiproliferative activity of diiron bis-cyclopentadienyl bis-carbonyl complexes containing a bridging vinyliminium ligand. This class of compounds possesses several ideal characteristics for a potential drug, making them promising and deserving of further studies aimed to optimize the anticancer behaviour.

\section{What aspects of this project do you find most exciting?}

Viewing something "old" in a "new" light may lead to unexpected opportunities and stimulating perspectives. Diiron compounds derived from $\mathrm{Fe}_{2} \mathrm{Cp}_{2}(\mathrm{CO})_{4}\left(\mathrm{Cp}=\eta^{5}-\mathrm{C}_{5} \mathrm{H}_{5}\right)$ belong to a traditional organometallic chemistry, which was intensively explored and rigorously developed in the last decades. Since many organometallic compounds usually decompose in the presence of air and/or moisture, inert atmosphere and anhydrous conditions were considered as compulsory for those former studies, ruling out possible biological applications. Our story started 16 years ago, when Fabio Marchetti was a PhD student dealing with the synthesis and the reactivity of the first diiron vinyliminium compounds, easily available from
$\mathrm{Fe}_{2} \mathrm{Cp}_{2}(\mathrm{CO})_{4}$ in a few steps. During the successive years, we have become aware of the fact that such species are air-stable and inert in aqueous solutions. One day, scientific curiosity triggered us to check the cytotoxicity of one tentative compound: the obtained results encouraged us to go deeper, prepare new complexes and expand these studies.

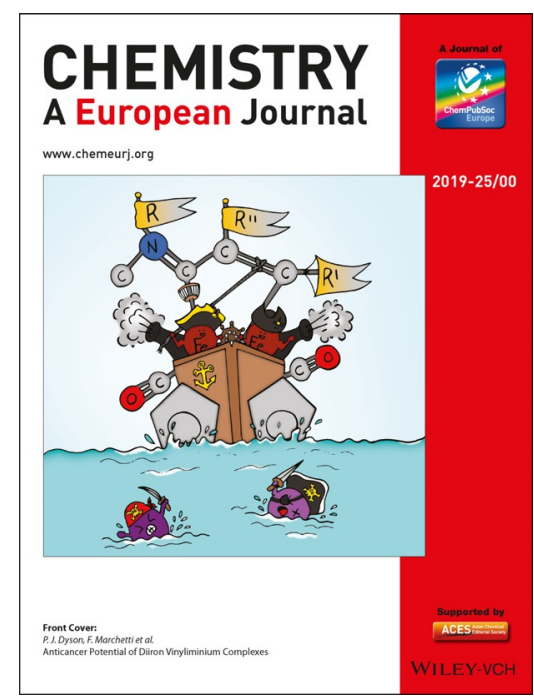

(c) 2019 Wiley-VCH Verlag GmbH \& Co. KGaA, Weinheim 